\title{
A HERITAGE INVENTORY FOR DOCUMENTING ENDANGERED ARCHAEOLOGY IN THE MIDDLE EAST AND NORTH AFRICA
}

\author{
N. Sheldrick ${ }^{a}$ and A. Zerbini ${ }^{b}$ \\ Endangered Archaeology in the Middle East and North Africa Project, \\ School of Archaeology, University of Oxford, 36 Beaumont St., Oxford, UK, OX1 2PG \\ a nichole.sheldrick@arch.ox.ac.uk b andrea.zerbini@arch.ox.ac.uk
}

\section{Commission II}

KEY WORDS: Endangered Archaeology, Middle East, North Africa, heritage inventory, Arches, open-access

\begin{abstract}
:
The heritage of the Middle East and North Africa is under growing threat from a variety of factors, including agricultural expansion, urban development, looting, and conflict. Recording and documenting this heritage is therefore a key priority to aid heritage practitioners tasked with protecting sites and evaluating their condition on the ground. The Endangered Archaeology in the Middle East and North Africa (EAMENA) project has developed a methodology for the identification, documentation, analysis, and monitoring of sites across the region to aid heritage professionals in these efforts. The project uses remote sensing techniques along with traditional archaeological research and prospection methods to collect data, which are stored and managed in a customdesigned database adapted from open-source Arches v. 3 software, using CIDOC CRM standards and controlled vocabularies. In addition to these activities, the EAMENA project has initiated an international conference series and training workshops to support and establish partnerships with heritage professionals and institutions across the region.
\end{abstract}

\section{INTRODUCTION}

The heritage of the Middle East and North Africa (MENA) is under growing threat as a result of a number of factors including agricultural expansion, urban development, looting, and conflict. Recording and documenting this heritage is a key priority in order to aid heritage practitioners tasked with protecting sites and evaluating their condition on the ground. Heritage inventories also have an important role to play in influencing the decisions of policymakers who draw up infrastructural development plans, e.g. for new dams, roads, industrial complexes, and residential areas.

Established in early 2015, the Endangered Archaeology in the Middle East and North Africa (EAMENA) project (http://eamena.arch.ox.ac.uk/) has developed a methodology for the identification, documentation, analysis, and monitoring of heritage sites across the MENA region, from Mauritania to Iran, and Syria to Yemen. This work combines a digital workflow using remote sensing techniques along with traditional archaeological research and prospection methods to collect data, which are then entered into a custom-designed Arches database and made available online (http://www.eamenadatabase.arch.ox.ac.uk). The database was launched to the public on 28 April 2017 as part of the first Public Archaeology Twitter Conference.

Site records are created by combining analyses of satellite imagery with a range of other sources, including published archaeological reports and historical aerial photographs. Data recorded in the EAMENA database include: site location, function, morphology, chronology, and detailed condition and threat assessments. Basic information about each site and its condition is available online to the public; access to the full site records is restricted to registered users to protect sensitive information, particularly exact site locations.

\section{THE EAMENA METHODOLOGY}

The activities and methods of the EAMENA project can be broken down into three main categories which can be related directly or indirectly to various parts of the heritage conservation process: Data Collection and Analysis, Information Management, and Dissemination and Outreach.

\subsection{Data Collection and Analysis}

The EAMENA project documents immovable archaeological and heritage sites dating from the Palaeolithic to the Second World War and collects data from a range of sources. In particular, the project's analysts use sets of freely-available, dated satellite imagery to identify sites of cultural heritage significance and record their changing condition through time.

Remote sensing techniques have been used successfully for archaeological investigations in the MENA region for many years (see, for example, Allan \& Richards, 1983; Wilkinson, 1997; Beck et al. 2007; Sterry \& Mattingly 2011) and recent, large-scale survey projects such as the Fragile Crescent Project (University of Durham) and the Trans-Sahara Project (University of Leicester) have demonstrated the scope of what can be achieved with this resource. In terms of heritage management, the EAMENA project has emphasised remote sensing as our primary technique for the identification and recording because it offers two main advantages. The first is accessibility: many parts of the MENA region are not accessible for study in the field to local or foreign academics due to the on-going conflicts. The increasing availability of satellite imagery and advances in the technology over the last 
20 years have made it possible to continue to collect data and conduct research via high-resolution, up-to-date images of sites without needing to visit and thus continue to support our incountry colleagues.

The second advantage of a remote-sensing methodology is its efficiency in terms of both time and cost. A single person can survey several square kilometres of land via satellite imagery and record dozens of sites within a day. Combined with the use of free imagery available via open-access, user-friendly platforms such as Google Earth or Bing Maps, this means that our primary data collection methodology is easily replicable, even for institutions or groups with limited resources.

In addition to remote sensing techniques, the project also draws upon data extracted from published and unpublished survey and excavation reports, partnerships with other archaeological teams, and our own fieldwork, which has so far been undertaken in Jordan, Lebanon, and Morocco. Partnerships with in-country authorities have also led to agreements involving the transfer of digital datasets into the EAMENA database. Incorporating these data allow us to confirm and cross-check information that has been collected using remote sensing techniques, and to enhance these records with more detailed information compiled and collected by incountry partners and other regional experts.

\subsection{Information Management}

The EAMENA Project has adapted the Arches v.3 heritage management software (developed by the Getty Conservation Institute and the World Monuments Fund, archesproject.org) as the foundation of its database. Arches was launched in 2013 with the aim to provide an easy-to-use geospatial inventory to heritage authorities across the world (Myers et al. 2012; 2016). At present, Arches has reached version 4 (released as a beta in March 2017). The main advantages of Arches are its being open-source - a fact that is attracting a growing user base and development community; ${ }^{1}$ its reliance on an international standard, the CIDOC Conceptual Reference Model (CRM) as the underlying schema for its relational database (Le Boeuf et al. 2017); and the flexibility of the framework on which it is built, which opens it up to customisations of any kind on the part of the end user.

Currently, the EAMENA deployment of Arches holds over 150,000 records, comprising both site data and information resources (such as bibliography, imagery, and cartography). EAMENA's customisations to the standard Arches platform have gone in three directions. First, starting from the Archesdesigned CIDOC CRM resource graphs, the project has created its own graphs in order to better represent the nature of the

1 Among the projects that have adopted Arches, Zbiva (http://zbiva.zrcsazu.si/ accessed 12/03/17) is particularly worth mentioning as it represents the first publicly-available Arches deployment of a traditional archaeological relational database (of early Medieval funerary contexts from the Eastern Alps and northern Balkans) established in the 1980s, and mapped to CIDOC CRM with the help of the European-funded project Ariadne (http://portal.ariadneinfrastructure.eu/page/24054304 accessed 12/03/17). Another deployment worth mentioning is that by the ASOR Cultural Heritage Initiative project (http://www.asor-syrianheritage.org/ accessed 12/03/17): this project, which, like EAMENA, uses remote sensing to evaluate the changing condition of heritage sites across Syria and Iraq, has yet to release its Arches implementation. information recorded by the project. During the first two years of the project, EAMENA had chiefly modified the Arches graph known as 'Heritage Resource Group' (downloadable at this link: http://archesproject.org/wpcontent/uploads/2013/11/Arches_v3_pdfs.zip, accessed 29 May 2017), which centres on the CIDOC class called 'Site E27' (Le Boeuf et al. 2017: 16; Zerbini 2016), However, since the beginning of 2017, the need has arisen to develop a more complex recording strategy for heritage resources, centred on a three-tier hierarchy of heritage groups (e.g. a settlement), heritage features (e.g. a church within the settlement) and heritage components (e.g. a wall within the church). While EAMENA heritage groups are still represented via a modified version of the Arches 'Heritage Resource Group' graph, the nature of information pertaining to heritage features and components is described by two completely new graphs, centred on the CIDOC CRM classes E24 ('Physical Man-Made Thing', Le Boeuf et al. 2017: 14) and E25 ('Man-Made Feature', Le Boeuf et al. 2017: 15).

The second area in which the EAMENA project has been making changes to the standard Arches package is in the controlled vocabularies, or thesauri, which drive the drop-down lists available to the end user via the user interface. The EAMENA project relies on ca. 2,300 core concepts to describe elements as different as chronologies, interpretations, disturbances, and threats. The EAMENA database and its vocabularies are currently available in both Arabic and English, with plans to add both Kurdish and Farsi, in order to facilitate and encourage use of the platform within MENA countries (Mahdy \& Zerbini, 2016).

Finally, the third area of customisation has concerned the development of the Arches v. 3 codebase to address projectspecific requirements. An important development was made in the area of data protection. Ahead of the EAMENA database online launch concerns had been raised that site reports, which contain accurate spatial data pertaining to the location and extent of heritage resources, might be used for illicit purposes (e.g. by looters). Zoom restrictions to unlogged users, were the first to be applied. However, since geographical coordinates of sites are served to the end user in clear as WKT coordinates, it remained possible for IT-savvy users to easily obtain site coordinates, by simply inspecting the HTML source of a site report page. To solve this, an encryption routine has been implemented drawing on the PyCrypto library (https://pypi.python.org/pypi/pycrypto, accessed 29 May 2017): coordinates are encrypted just before being served to the frontend user interface, and then get decrypted programmatically via Javascript, drawing on the functionalities provided by the CryptoJS library (https://code.google.com/archive/p/crypto-js/ accessed 13 March 17).

Another significant change concerns the development of an 'advanced search' toolset. Currently, the Arches search, which is powered by Elasticsearch (the search engine used by companies such as Facebook, Netflix, and GitHub), allows the concatenation of tags in 'AND' search queries. The new search toolbox developed by EAMENA allows for both 'AND' and 'OR' queries to be produced. Moreover, the user is able to search within nested groups of values, a feature not previously present in Arches. The absence of this capability had led to some issues in querying the EAMENA dataset: for example, if one wished to search for all EAMENA sites where 'Clearance 
(Bulldozing/Levelling)' (a disturbance cause in the EAMENA methodology of documentation) has produced a 'Loss of Archaeological Material' (a disturbance effect), the resulting search query would yield not only the expected results, but also any site in which the disturbance cause 'Clearance (Bulldozing/Levelling)' and the disturbance effect 'Loss of Archaeological Material' appear, even though they may not be necessarily linked one to the other.

Another key area of customisation currently under development regards the implementation of a synchronisation tool. This is meant to allow users to install the EAMENA-modified Arches app on their computers as a stand-alone platform which may be used both online and offline: when a reliable internet connection is available, the user will be able to sync the offline app with the online database, thus saving online any changes made when offline.

A final important area of development is 'versioning', namely the ability to save multiple versions of a database's content as the latter gets updated by the user. This feature will allow the app's users to browse through multiple versions of a site report instead of just seeing - as it is currently with Arches - its latest and most updated version. It is expected that this feature will prove of crucial value for heritage managers, who will be able to look through older site reports in order to find out, for example, how a site's condition assessment has evolved through time.

Many of these modifications are essential to strengthen the case for the adoption of the EAMENA Database as the baseline framework for heritage inventories and management platforms in the countries in which EAMENA operates.

The EAMENA customisations to the Arches v.3 software may be downloaded from the project's GitHub repository (https://github.com/azerbini/eamena_v3). As EAMENA migrates to the new Arches v.4 over the course of 2018, we are hopeful that we will be able to repackage these customisations to make them available to the wider Arches v. 4 community.

\subsection{Dissemination and Outreach}

As of April 2017, the EAMENA database is accessible online and open-access, though there are restrictions on sensitive information such as exact site locations. Our documentation provides a foundation of data from which stakeholders who are in a position to make decisions about cultural heritage conservation in individual countries or regions can make informed decisions about the need for and urgency of appropriate interventions. It also provides a platform where any interventions can then be recorded and the condition of sites can continue to be monitored.

Furthermore, EAMENA has set up an international series of conferences and workshops entitled 'Protecting the Past', the aim of which is to raise awareness on issues of cultural heritage documentation and protection, as well as to disseminate the results of the project's work (http://www.protectingthepast.com). The first two events of this series were held in Amman (2015) and Sulaimaniyeh (2016), the latter also including a training session for students and heritage professionals in the methodology of data acquisition pioneered by EAMENA (Bewley, et al., 2016;
Zerbini, Bradbury, \& Cunliffe, 2016). Planning is underway for a third event to take place in Tunis in November 2017.

Following the award of a British Council Cultural Protection
Fund (https://www.britishcouncil.org/arts/culture-

development/cultural-protection-fund), the EAMENA team, with its training managers, will also be providing in-depth training in imagery interpretation and site documentation to heritage professionals from Tunisia, Libya, Palestine, Lebanon, Syria, Iraq, and Jordan. Participants will be provided with laptops and all of the necessary software, and will be trained in the EAMENA methodology and database in sets of two-week training workshops. In addition to the technical training, a key part of the workshops will be to discuss with the participants about how these tools can be usefully incorporated into existing heritage practices within their own countries and regions, and get feedback about ways in which our methodologies can be adapted or improved to address specific issues or challenges that they face in their own work. The first of these workshops will take place in Tunis in late 2017, with further workshops in Amman and Beirut in 2018.

\section{OUTCOMES}

The EAMENA methodology and database, which has so far enabled the rapid identification and documentation of thousands of sites across diverse landscapes (Figure 1), has numerous potential applications for both the field of heritage conservation and planning, as well as academic research.

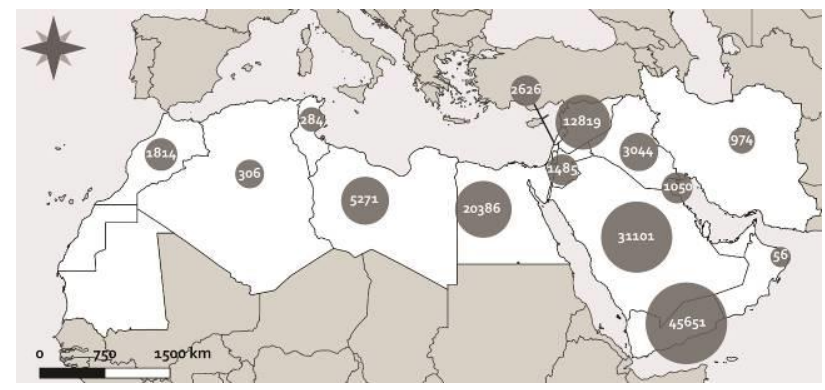

Figure 1. Distribution of archaeological sites recorded in the EAMENA database as of July 2017.

Our in-depth surveys of satellite imagery and aerial photography have been instrumental in creating documentation for preventive field surveys conducted by local authorities ahead of infrastructural development. For example, the EAMENA team were able to provide a report detailing sites which could be affected by the construction of a ring road around Madaba in Jordan, some of which were previously unknown to local authorities, enabling them to make a survey of the sites before development began (Zerbini \& Banks, 2015).

Other case studies being undertaken by the EAMENA team have also begun to demonstrate the enormous potential for our database to highlight the richness of the archaeological record for sites and landscapes that have traditionally received less attention than other, high-profile examples, especially in rural contexts, and to bring attention to the many and complex problems facing them. 
A recent study undertaken by EAMENA members on western Libya demonstrated both the wide variety of archaeological resources present within a single country, and the many threats facing those sites, including armed conflict, natural erosion, and most seriously in this case, urban development and agricultural expansion (Figure 2). Of more than 700 sites assessed in four areas of Libya, over a third were determined to be in poor condition or worse (Rayne, Sheldrick, \& Nikolaus, 2017). The largest proportion of these were identified around the Jufra and Murzuq oases, where the rate of urban and agricultural expansion has increased dramatically since 2011, following the break-down of the restrictive policies on property ownership that had been in place under the Qaddafi regime (Fitzgerald \& Megerisi, 2015).

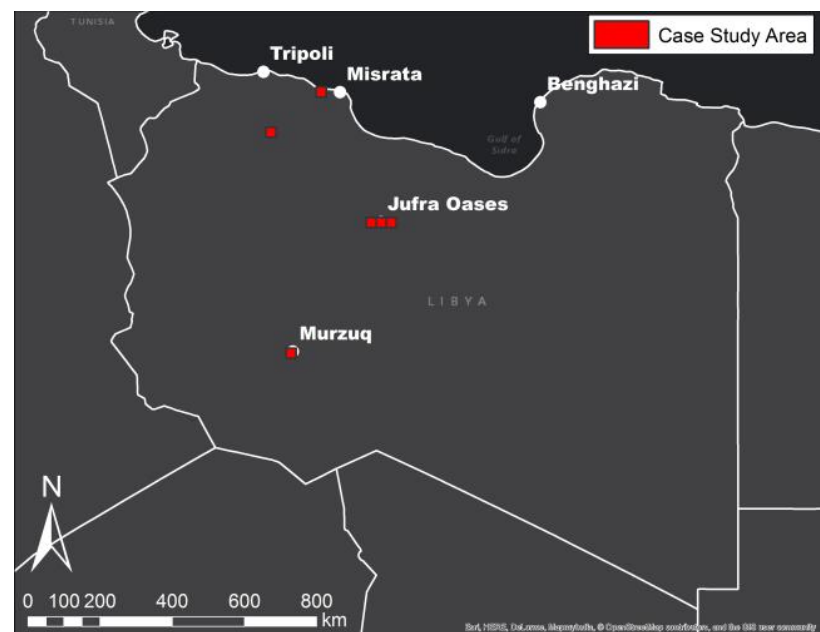

Figure 2. Location of case study areas in Libya (Basemap: Esri, HERE, DeLorme, MapmyIndia, () OpenStreetMap contributors, and the GIS user community).

Similarly, on-going work in the Eastern Desert of Egypt has highlighted the main threats facing the archaeology of that area, primarily ancient mining sites and settlements, which have generally received far less attention than the more wellknown sites of the Nile Valley and Delta. In a single case study of one area of the Eastern Desert, more than 400 certain and possible archaeological sites were identified, most of which were previously unrecorded (Figure 3). Of these, $43 \%$ were already destroyed by 2016, and a further $14 \%$ were in very bad or poor condition (Figure 4); preliminary examination suggests that this situation is typical across much of the region. However, while in the Nile Valley and Delta regions looting and urban and agricultural expansion pose the greatest threat, the main activities that have affected the archaeological sites recorded in the Eastern Desert are modern mining and quarrying, and it is clear that a different approach will be necessary to address and mitigate these issues (Fradley \& Sheldrick, 2017).

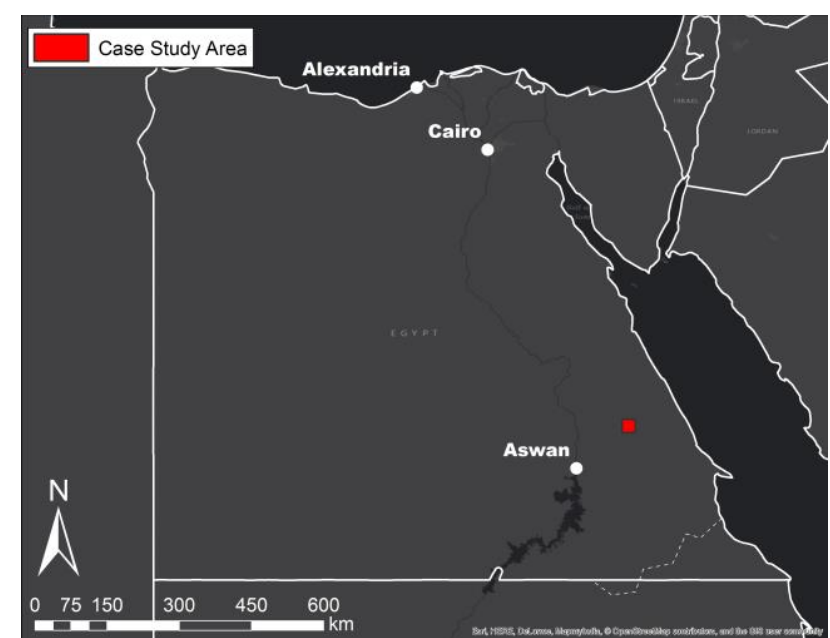

Figure 3. Location of case study in the Eastern Desert of Egypt

(Basemap: Esri, HERE, DeLorme, MapmyIndia, (C)

OpenStreetMap contributors, and the GIS user community).

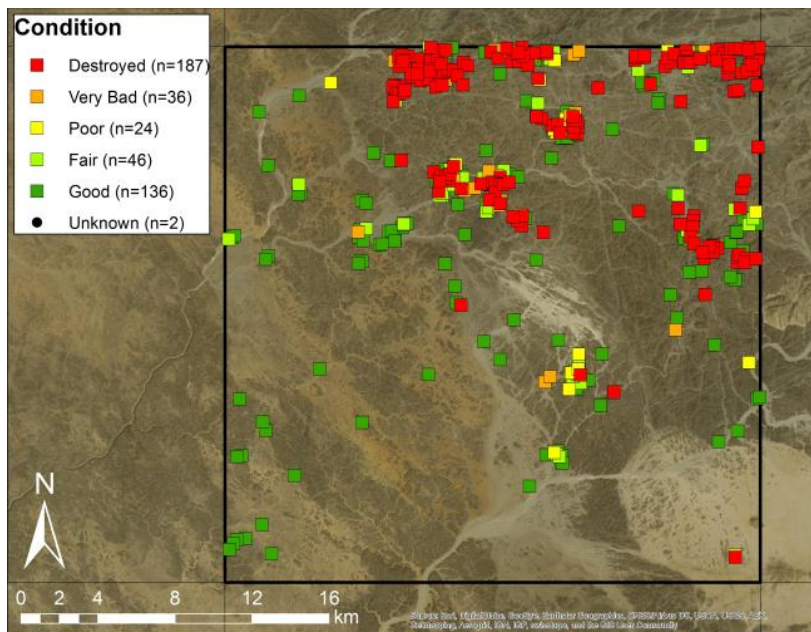

Figure 4. Distribution of sites by condition (Basemap: Esri, DigitalGlobe, GeoEye, Earthstar Geographics, CNES/Airbus DS, USDA, USGS, AEX, Getmapping, Aerogrid, IGN, IGP, swisstopo, and the GIS User Community).

The Libyan and Egyptian case studies just described are only two brief examples which demonstrate how the EAMENA database and methodology can be used to produce useful datasets and analyses that provide an important baseline of information for heritage management purposes. However, this is only the first step, and these examples also serve to emphasize the importance of working directly with in-country partners to understand how this type of methodology and the data that it produces can best be integrated into existing practices and applied to the protection and management of heritage resources in real-world situations, as demonstrated in the case of the Madaba Ring Road study.

Substantial progress has already been achieved in Yemen where, under the overall coordination of UNESCO (Doha office), EAMENA has been teaming up with the General Organisation for Antiquities and Museums (GOAM) based in Sanaa and with the international archaeological community to create a heritage inventory for the country. Drawing upon the large dataset collected by EAMENA via remote sensing (ca. 40,000 sites) as well as on field-collected data provided by archaeologists, a stand-alone platform provisionally named 
YHMP (Yemen Heritage Management Platform) has been developed. Currently, the codebase of this platform presents no differences with EAMENA's. However, a technical team made up of policymakers, IT experts and archaeologists from Yemen or with field experience in the country is currently in the process of compiling detailed feedback, in order to make this platform more suited to the needs of the Yemeni authorities.

\section{CONCLUSIONS}

Using the methods and workflows outlined above, the ultimate goal of the EAMENA Project is to create an inventory that will be of use to local heritage authorities across the MENA region for the protection and conservation of heritage sites, and in particular, we want to support those who, whether through war or lack of resources, may not otherwise be able to muster the resources necessary to develop or maintain such platforms, by providing access to our database and/or aiding in the development of independent national inventories. By developing a MENA-region-wide heritage inventory, we will be able to analyse both country-specific and region-wide processes, which are necessary to identifying, understanding, and ultimately, mitigating the causes of heritage damage and destruction.

\section{ACKNOWLEDGEMENTS}

The EAMENA project is based at the Universities of Oxford, Leicester, and Durham, and is generously supported by the Arcadia Fund (https://www.arcadiafund.org.uk/) and the British Council's Cultural Protection Fund (https://www.britishcouncil.org/arts/culture-

development/cultural-protection-fund). The authors wish to thank all of the members of the EAMENA team (http://eamena.arch.ox.ac.uk/meet-the-team/) for their work and contributions and we are grateful to all those who commented on drafts of this paper. Any errors remain our own.

Maps in this article were created using ArcGIS $®$ software by Esri. ArcGIS ${ }^{\circledR}$ and $\operatorname{ArcMap}^{\mathrm{TM}}$ are the intellectual property of Esri and are used herein under licence. Copyright (C) Esri. All rights reserved. For more information about Esri ${ }^{\circledR}$ software, please visit www.esri.com.

\section{REFERENCES}

Allan, J.A. \& Richards, T.S., 1983. Use of Satellite Imagery in Archaeological Surveys. Libyan Studies, 14, pp. 4-8.

Beck, A., Philip, G., Absulkarim, M., \& Donoghue, D., 2007. Evaluation of Corona and Ikonos high resolution satellite imagery for archaeological prospection in western Syria. Antiquity, 81(1), pp. 161-175.

Bewley, R., Bradbury, J., Cunliffe, E., \& Zerbini, A., 2016. Training Workshop, $27^{\text {th }}-28^{\text {th }}$ October, Sulaimani, Iraqi Kurdistan. http://eamena.arch.ox.ac.uk/training-workshop27th-28th-october-sulaimani-iraqi-kurdistan/ (1 Feb. 2017).

Fitzgerald, M. \& Megerisi, T., 2015. Libya: Whose Land Is It? Property Rights and Transition. Legatum Institute, London. www.li.com/events/libya-whose-land-is-it (15 Feb. 2017).
Fradley, M. \& Sheldrick, N., 2017. Satellite imagery and heritage damage in Egypt: a response to Parcak et al. (2016). Antiquity, 91(357), pp. 784-792.

Mahdy, H. \& Zerbini, A., 2016. Translating EAMENA's platform into Arabic: challenges and solutions. http://eamena.arch.ox.ac.uk/translating-eamenas-platform-intoarabic-challenges-and-solutions/ (1 Feb. 2017).

Myers, M., Dalgity, A., Avramides, I., \& Wuthrich, D., 2012. Arches: An Open Source GIS for the Inventory and Management of Immovable Cultural Heritage. In: Progress in Cultural Heritage Preservation: 4th International Conference, EuroMed 2012, Lemessos, Cyprus, October 29- November 3, 2012, Proceedings, pp. 817-824. http://archesproject.org/wpcontent/uploads/2013/01/Arches-EuroMed-2012.pdf (29 May 2017).

Myers, M., Dalgity, A. \& Avramides, Y. 2016. 'Arches: A Free Software Platform Purpose-Built for Cultural Resource Inventories.' The Alliance Review, National Alliance of Preservation Commissions, Summer 2016, pp. 22-27.

Le Boeuf, P., Doerr, M., Ore, C.E., \& Stead, S., 2017. Definition of the CIDOC Conceptual Reference Model. http://www.cidoc-crm.org/sites/default/files/2017-0125\%23CIDOC\%20CRM_v6.2.2_esIP.pdf (29 May 2017).

Rayne, L., Sheldrick, N., \& Nikolaus, J., 2017 (forthcoming). Endangered Archaeology in Libya: recording damage and destruction. Libyan Studies, 48.

Sterry, M. \& Mattingly, D.J., 2011. DMP XIII: reconnaissance survey of archaeological sites in the Murzuq area. Libyan Studies, 42, pp. 89-116.

Wilkinson, T.J., 1997. Tell Beydar Survey. The Oriental Institute 1997-1998 Annual Report, pp. 19-28.

Zerbini, A., 2016. Designing our database http://eamena.arch.ox.ac.uk/designing-our-database/ (1 Feb. 2017).

Zerbini, A. \& Banks, R., 2015. The Madaba Ring Road, Jordan. Evidence of cultural heritage assets from remote imagery in the Madaba hinterland. http://eamena.arch.ox.ac.uk/the-madaba-ring-road-jordanevidence-of-cultural-heritage-assets-from-remote-imagery-inthe-madaba-hinterland/ (1 Feb. 2017).

Zerbini, A., Bradbury, J., \& Cunliffe, E., 2016. Protecting the Past 2 in Sulaimani. http://eamena.arch.ox.ac.uk/protectingthe-past-2-in-sulaimani/ (1 Feb. 2017). 